\title{
A plug-and-play high-pressure ESI source with emitter at ground potential and its application to high-temperature capillary LC-MS
}

\author{
Lee Chuin Chen ${ }^{1 *}$ \\ ${ }^{1}$ Interdisciplinary Graduate School of Medicine and Engineering, University of Yamanashi, 4-3-11, \\ Takeda, Kofu, Yamanashi, 400-8511 Japan
}

*Corresponding author:

L. C. Chen, Tel: +8155-220-8072, Email: leechuin@yamanashi.ac.jp

\section{Contents}

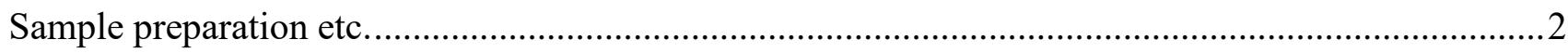

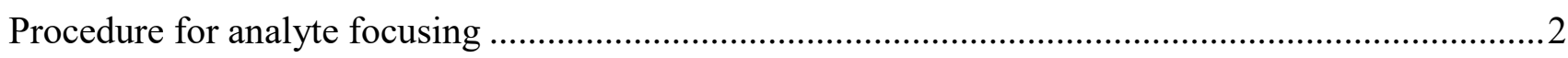

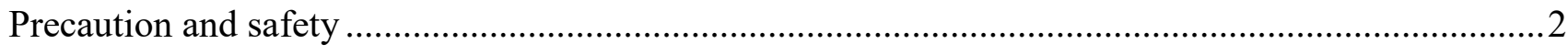

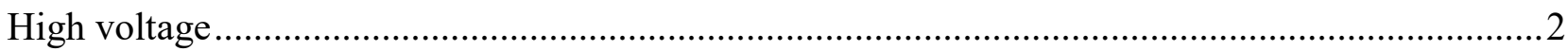

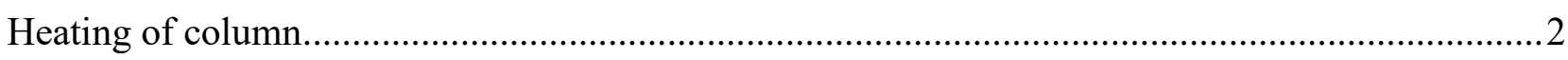

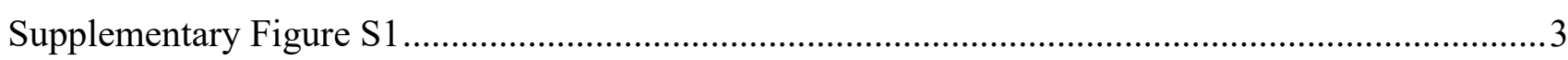

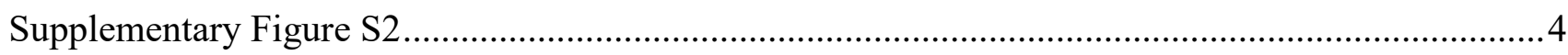

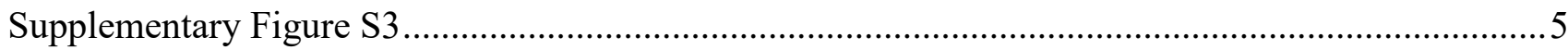

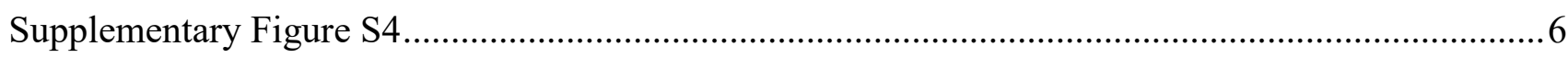

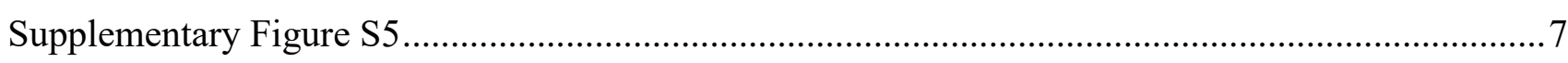

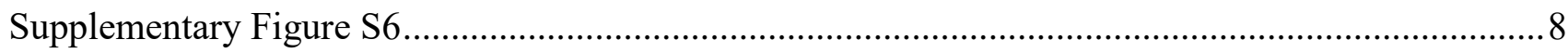

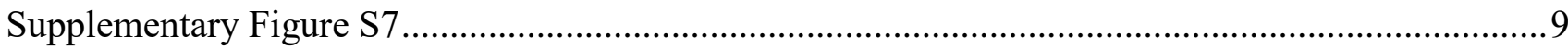

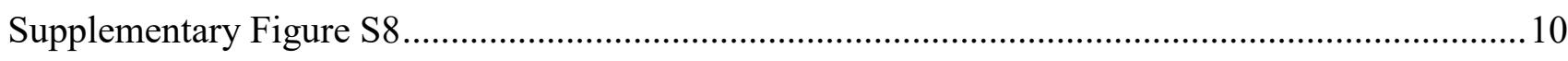

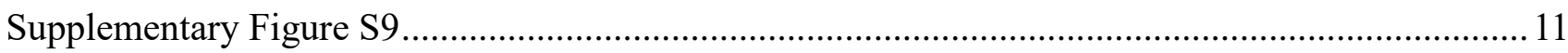




\section{Sample preparation etc.}

HPLC grade acetonitrile (ACN), $0.1 \% \mathrm{v} / \mathrm{v}$ formic acid (FA) and $0.1 \% \mathrm{v} / \mathrm{v}$ trifluoroacetic acid (TFA) were purchased from Fisher Scientific (Hampton, US). Human angiotensin I, equine myoglobin, bovine insulin, ubiquitin, and $\beta$-lactoglobulin were purchased from Sigma Aldrich (St. Louis, US) and bovine cytochrome c was from Wako (Osaka, Japan). All samples were used without further purification. Pure water was produced using Simplicity UV (Millipore, Burlington, US). For LC-MS analysis, samples prepared in $0.3 \sim 1 \mu \mathrm{M}$ in $0.1 \% \mathrm{v} / \mathrm{v}$ trifluoroacetic acid aqueous solution were filtered using a $0.2 \mu \mathrm{m}$ PTFE syringe filter (Millipore, Burlington, US) before filling into the vial for analysis. Typical solution flow rates were $5 \mu \mathrm{L} / \mathrm{min}$ for LC-MS and $2 \mu \mathrm{L} / \mathrm{min}$ for the performance evaluation of ion source.

The count of retention time started after the completion of the sample injection. The settings for the Exactive-Orbitrap were as follow: the temperature for the ion transport tube was $300{ }^{\circ} \mathrm{C}$, the inlet capillary, and tube lens voltages were $120 \mathrm{~V}$, and the skimmer voltage was $20 \mathrm{~V}$.

\section{Procedure for analyte focusing}

To reduce the pre-column dispersion, the following procedure was used: i) $1 \mu \mathrm{L}$ of the sample mixture $(1 \mu \mathrm{M}$ each) was first injected using a weak eluent $(<10 \% \mathrm{ACN})$ to concentrate the target compounds at the initial theoretical plates of the column. ii) After the first injection, $20 \mu \mathrm{L}$ of the actual mobile phase prepared in the vial was injected for elution. The mobile phase was ACN/water 4:8 v/v with $0.1 \%$ TFA. The count of retention started upon the completion of the first injection. The time it took for the actual mobile phase to reach the column was approximately $2.5 \mathrm{~min}$.

\section{Precaution and safety}

\section{High voltage}

The extractor electrode in the present ion source is applied with $>2 \mathrm{kV}$ from an external DC HV supply. A protecting resistor should be placed in between the electrode and the output of the power supply to reduce the damage of electric shock and accidental short circuit. A $50 \mathrm{M} \Omega$ resistor is used in this study.

\section{Heating of column}

Cavitation caused by the boiling of the mobile phase can cause irreversible damage to columns and frits. It is needed to make sure that the ion source is pressurized above the target vapor pressure before heating the column. 


\section{Supplementary Figure S1}

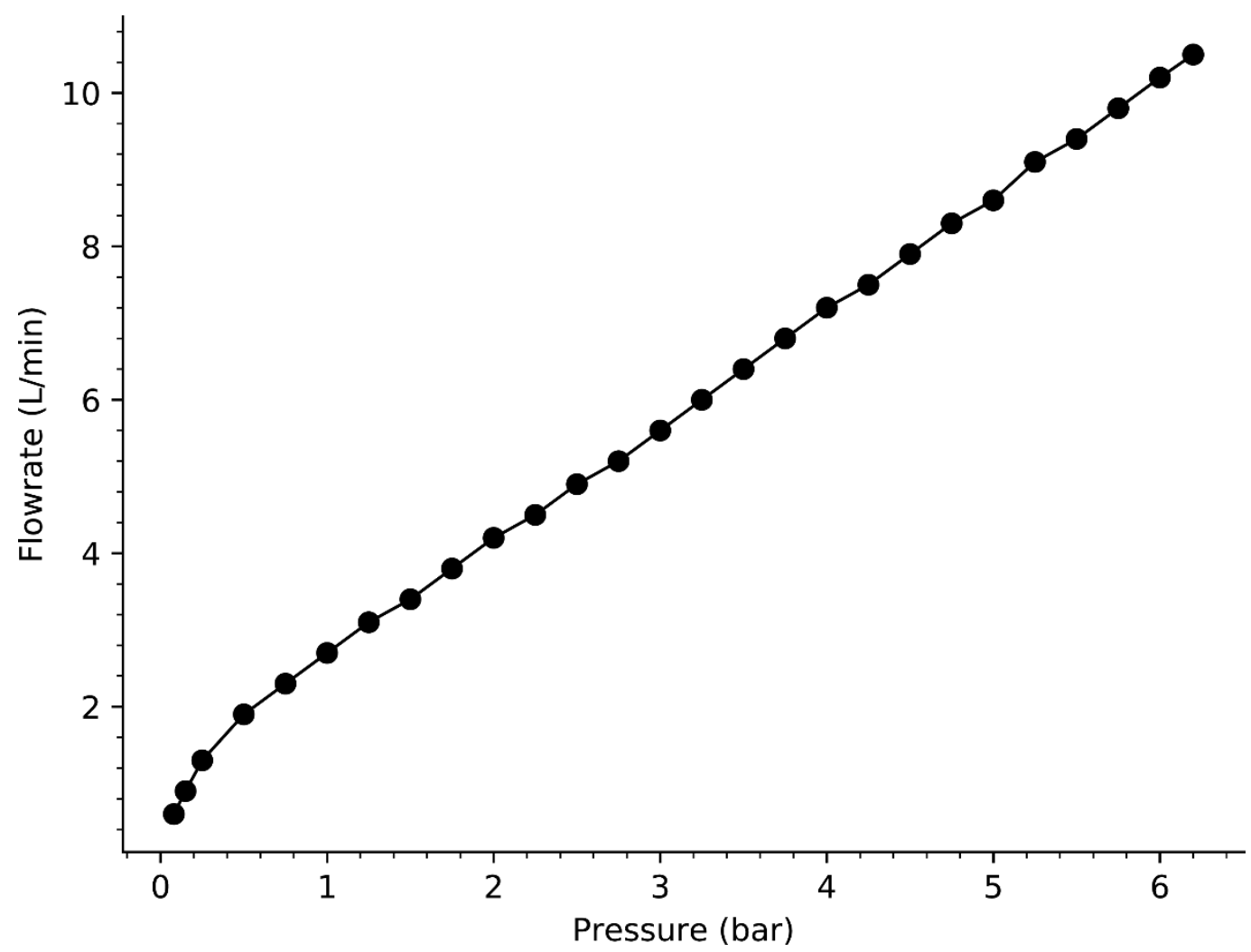

Figure S1. A plot of gas flow rates versus ion source gauge pressures. 


\section{Supplementary Figure S2}
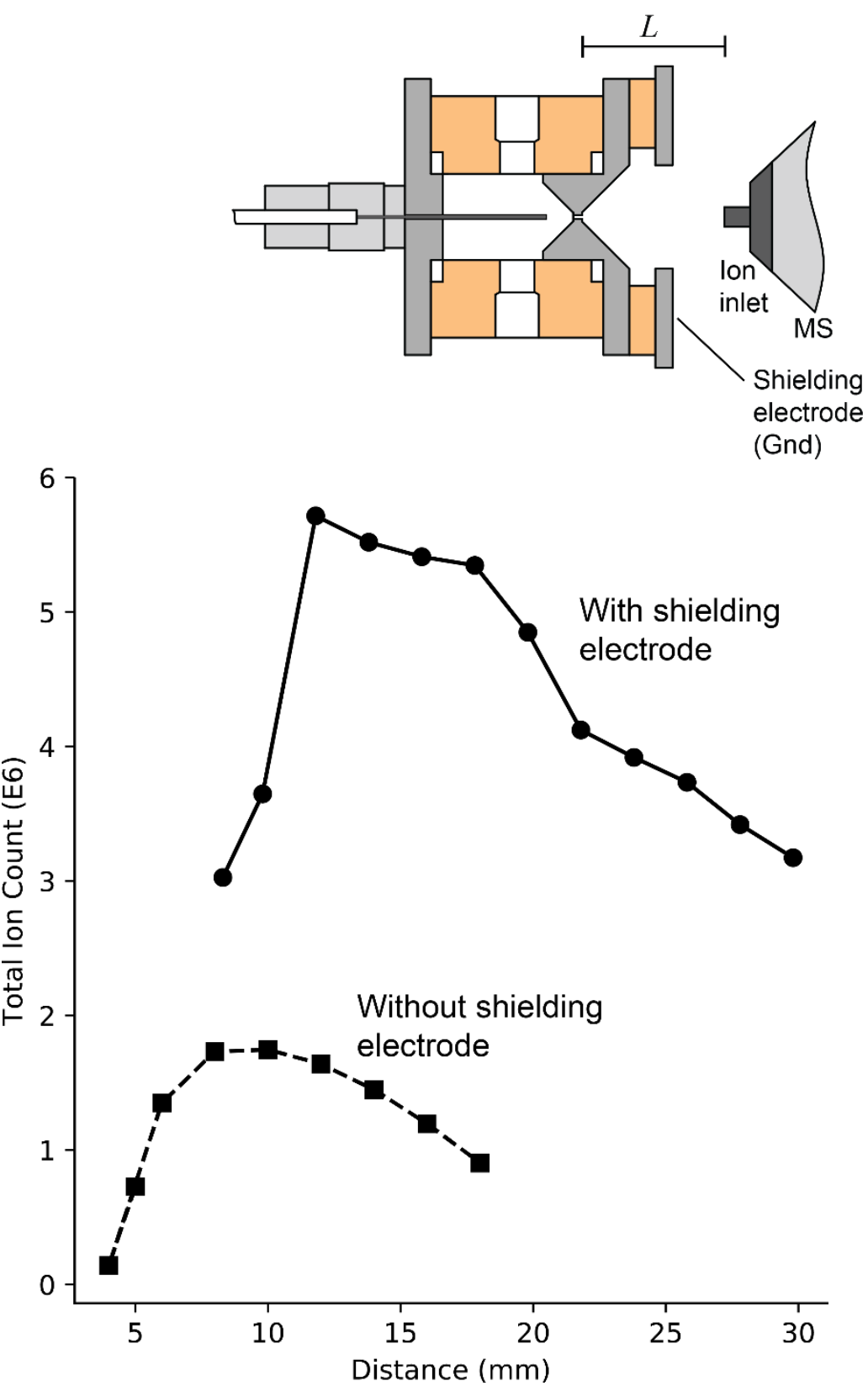

Figure S2. Changes of total ion intensity with the distance $L$ shown in the inset. $L$ is measured from the ion source outlet orifice to the ion inlet of the mass spectrometer. Sample: $0.3 \mu \mathrm{M}$ cytochrome $\mathrm{c}$ in $0.1 \%$ formic acid aqueous solution. Solid line (circle): with shielding electrode. Dashed line (square): without shielding electrode. Ion source gauge pressure: 1 bar. 


\section{Supplementary Figure S3}

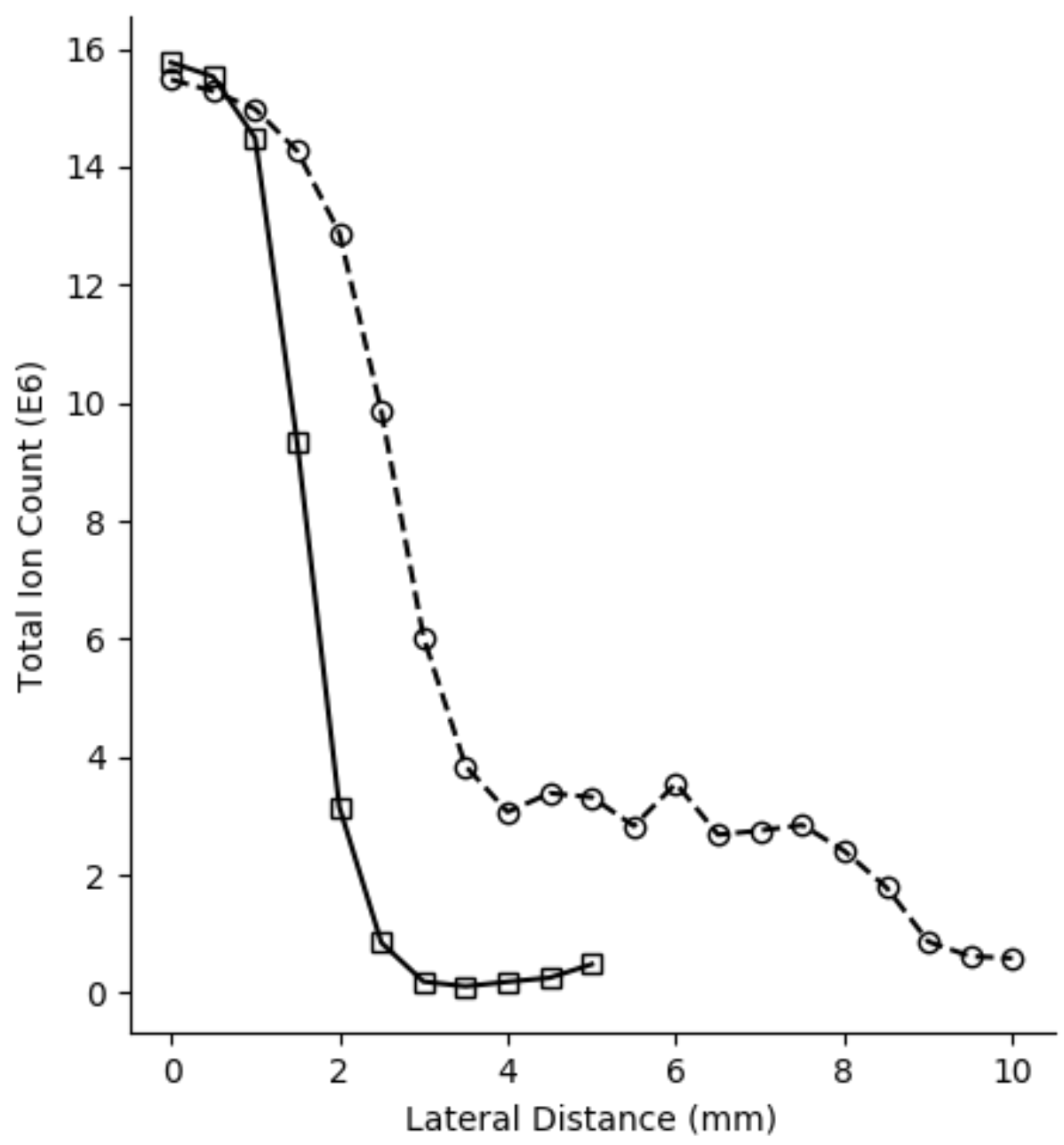

Figure S3. Changes of total ion signal with the lateral distance from the central axis. Distance between ion source outlet and ion inlet ( $L$ in the inset of Figure S2) is $14 \mathrm{~mm}$ for the solid line (square), and 20 $\mathrm{mm}$ for the dashed line (circle). Sample: $0.3 \mu \mathrm{M}$ cytochrome c in $50 \% \mathrm{v} / \mathrm{v}$ ACN with $0.1 \%$ formic acid. Ion source gauge pressure: 1 bar. 
a)

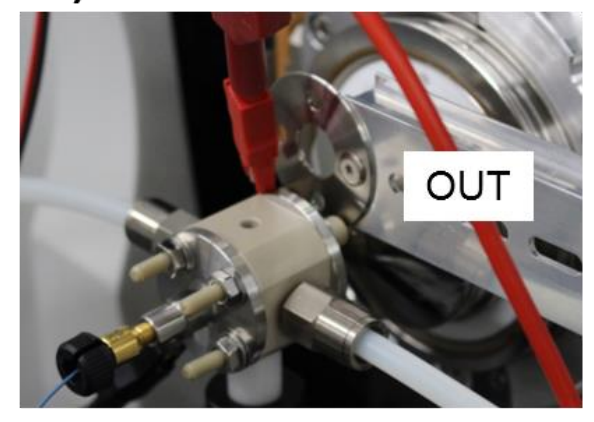

b)
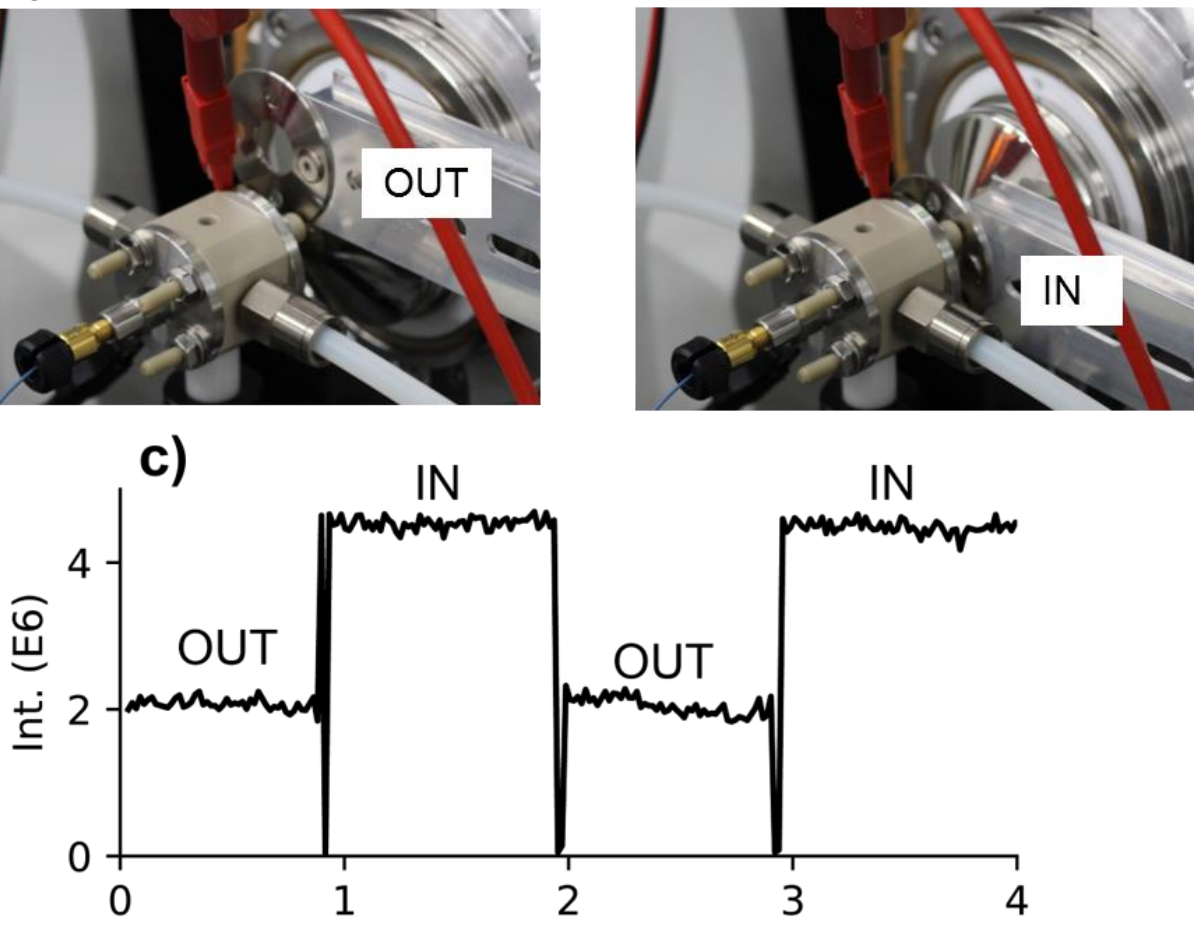

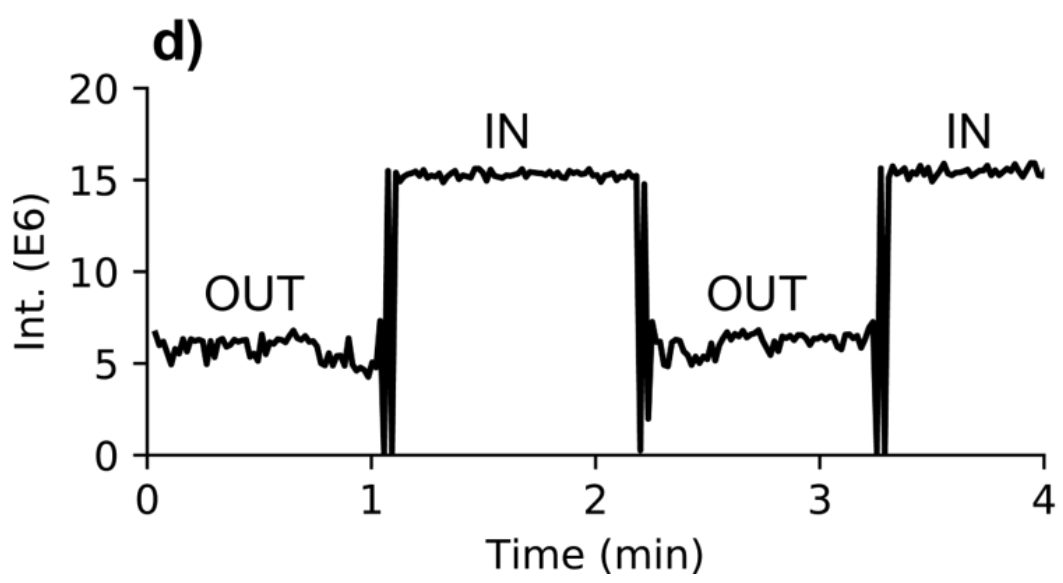

Figure S4. Effect of employing the shielding electrode.

a) Configuration of the experiment with the shielding electrode removed (OUT).

b) The shielding electrode is inserted between the ion source outlet and the MS inlet (IN).

c) TIC for the detection of $0.3 \mu \mathrm{M}$ cytochrome c prepared in $0.1 \%$ formic acid aqueous solution with and without the shielding electrode.

d) $\mathrm{TIC}$ for the detection of $0.3 \mu \mathrm{M}$ cytochrome c prepared in $50 \%$ acetonitrile with $0.1 \%$ formic acid with and without the shielding electrode. 


\section{Supplementary Figure S5}
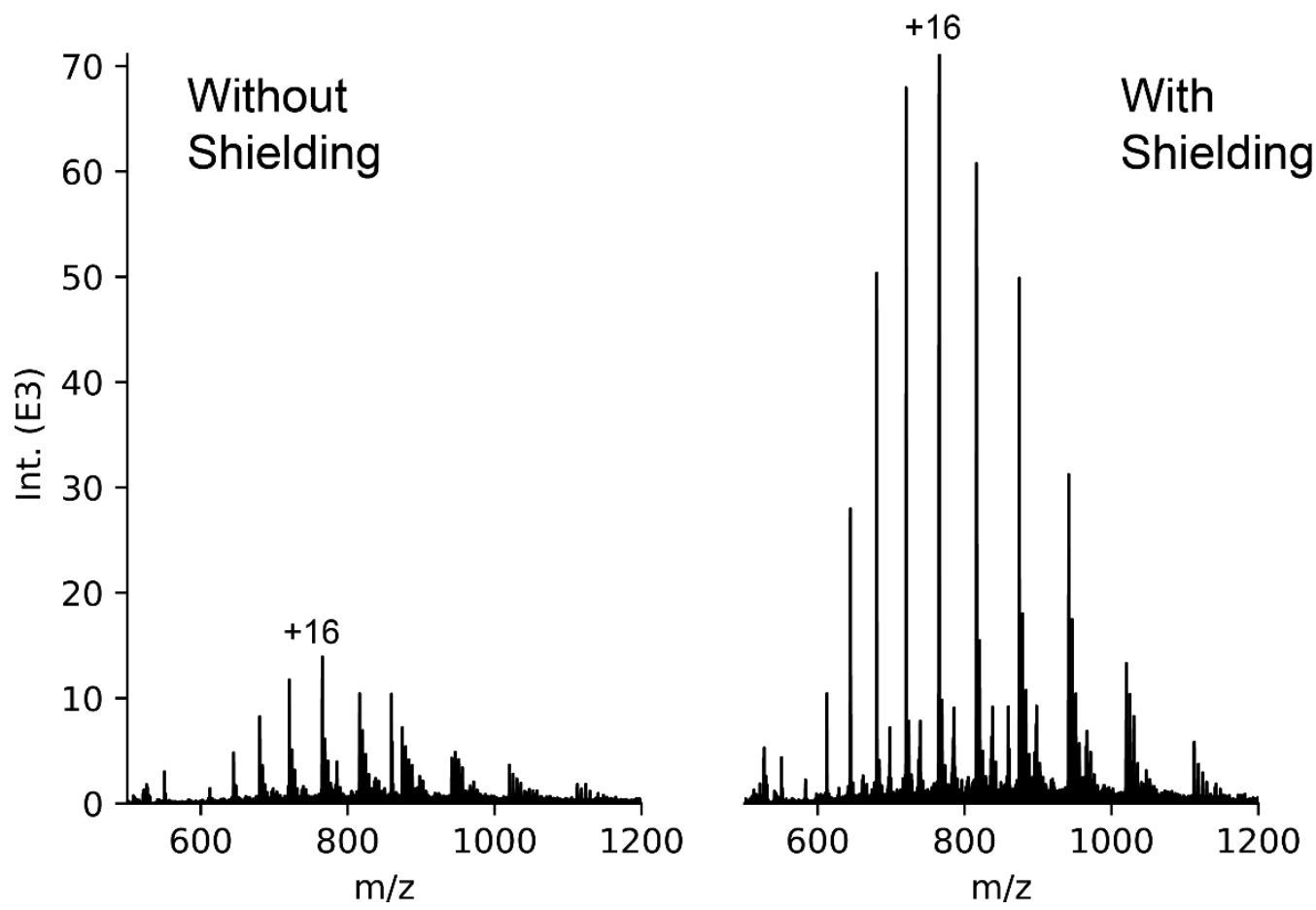

Figure S5. Mass spectra of $0.3 \mu \mathrm{M}$ cytochrome c prepared in $50 \% \mathrm{v} / \mathrm{v} \mathrm{ACN}$ with $0.1 \%$ formic acid, with and without the shielding electrode. 


\section{Supplementary Figure S6}

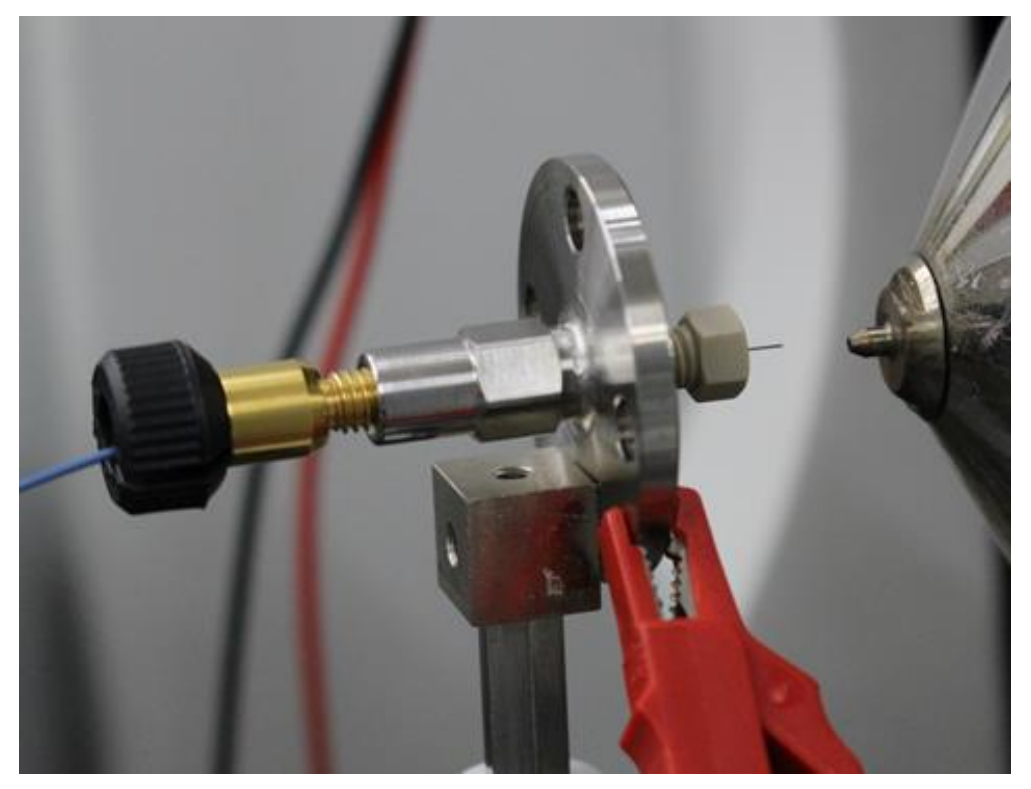

Figure S6. Configuration of the atmospheric pressure ESI using the emitter flange of the present ion source. The optimal distance between the emitter tip and the MS inlet is approximately $4 \mathrm{~mm}$. The H.V. is $3 \mathrm{kV}$. 


\section{Supplementary Figure S7}
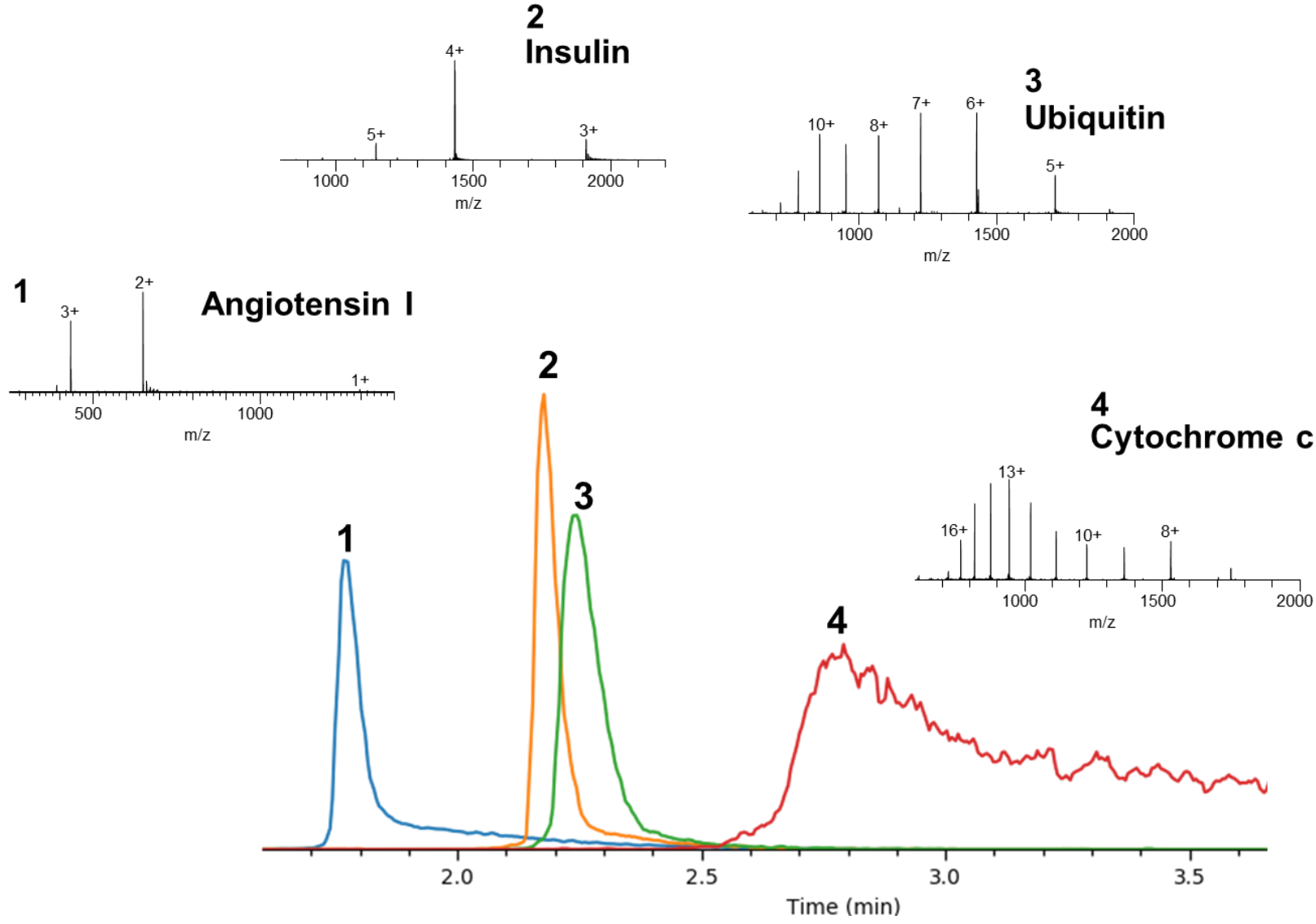

Figure S7. Mass spectra acquired at different LC peaks. 1: Angiotensin I, 2: Insulin, 3: Ubiquitin, 4: Cytochrome c. The temperature of the column is $110{ }^{\circ} \mathrm{C}$. Mobile phase: $20 \% \mathrm{w} / \mathrm{w}$ ACN in $0.1 \%$ TFA. Flow rate: $5 \mu \mathrm{L} / \mathrm{min}$ 


\section{Supplementary Figure S8}

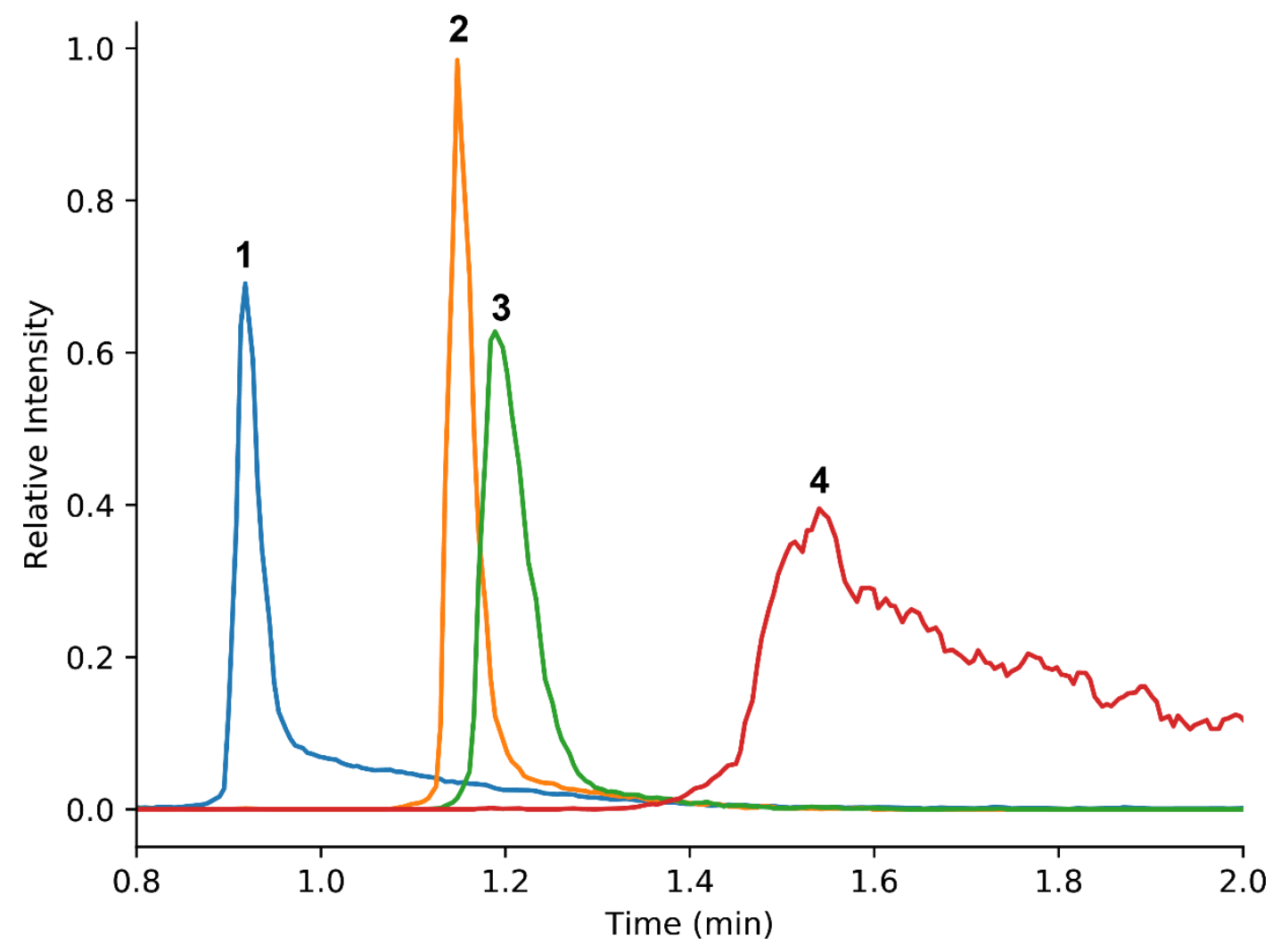

Figure S8. Extracted ion chromatogram for angiotensin $I(\mathbf{1},+2)$, insulin $(2,+4)$, ubiquitin $(\mathbf{3},+6)$, cytochrome c $(4,+13)$. Column temperature: $110^{\circ} \mathrm{C}$. Mobile phase flowrate: $10 \mu \mathrm{L} / \mathrm{min}$. LC System pressure: $13.6 \mathrm{MPa}$. 


\section{Supplementary Figure S9}

2) Cytochrome c
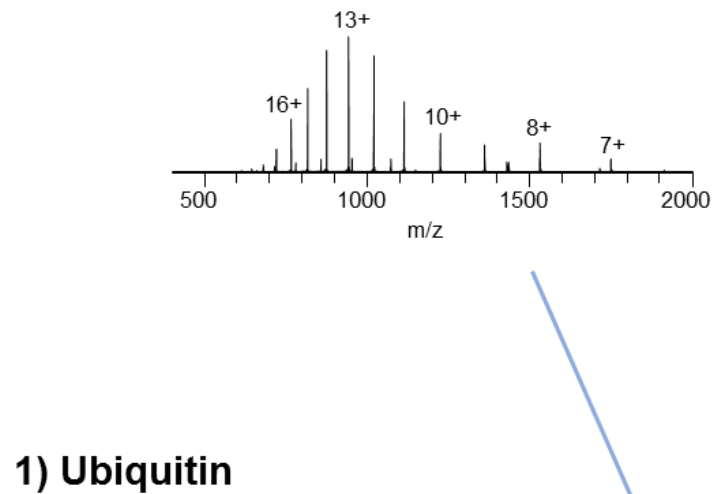

1) Ubiquitin
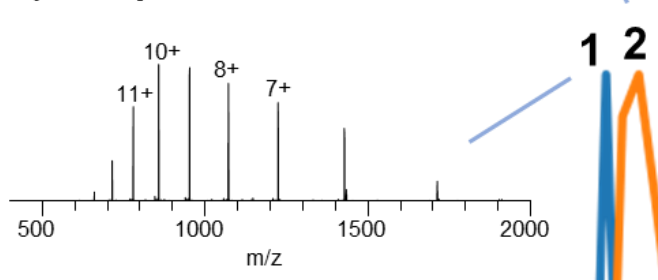

3.2

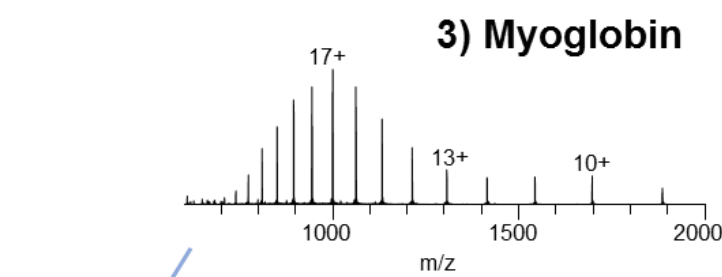

4) $\beta$-Lactoglobulin

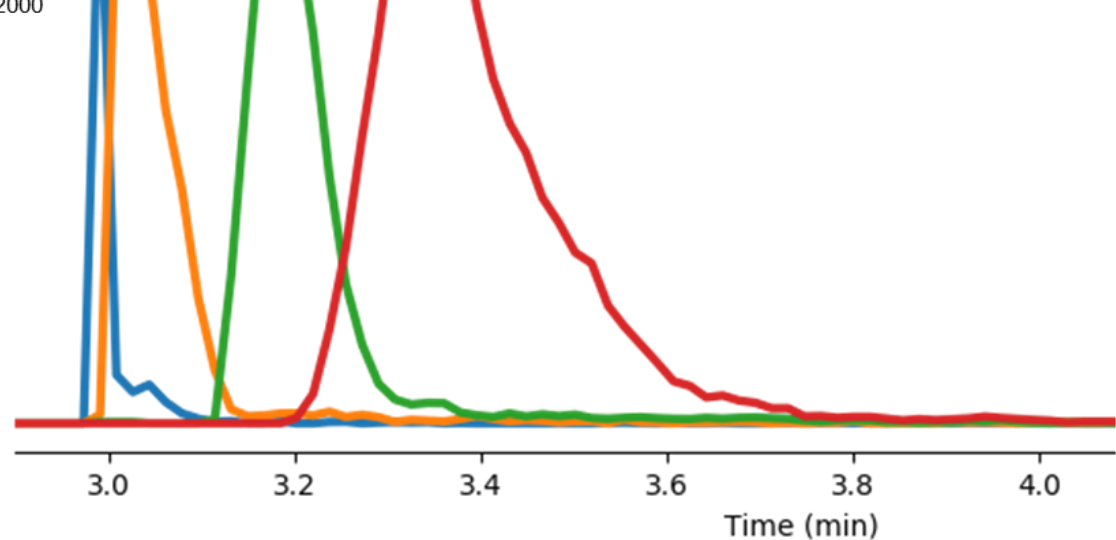

Figure S9. Mass spectra acquired at different LC peaks. 1: Ubiquitin, 2: Cytochrome c, 3: Myoglobin, 4: $\beta$-Lactoglubulin. The temperature of the column is $110^{\circ} \mathrm{C}$. Mobile phase: $\mathrm{ACN} /$ water $4: 8 \mathrm{v} / \mathrm{v}$ with $0.1 \%$ TFA. Flow rate: $5 \mu \mathrm{L} / \mathrm{min}$. 